\title{
Chapter 9 \\ Presentations
}

\section{Presentations: Remember all the bad presentations you have seen and accept that your presentation may be no better.}

Note: The slides in this section have been manipulated by me to make particular points. Some of the data reported in the slides are NOT accurate and do not necessarily reflect reality.

MISTAKE We all know what makes a bad presentation, but we seem to be blissfully unaware that we make exactly the same mistakes in our own presentations. Or even if we are aware, we find excuses for our own poor performance: I didn't have enough time to prepare. ... I know the slides are full of text, but I couldn't find a way to condense them. ... Yes, there are no images, but I couldn't find any non-copyrighted images. ... I even got bored myself while presenting it.... The presentation was bad even when I presented it in my own language. It is almost as if we take some kind of pride in the level of the disaster of our presentation, and we also expect others to understand this in the knowledge that they too have been in a similar situation.

Typical mistakes that presenters know that they make, include: but continue to make them anyway:

- No clear structure / No clear message

- No eye contact with audience

- Too much text - hard to find key info

- No images

- Presenter reads the text on the slides - word for word 
- Monotone voice + no enthusiasm

- Too long + too many technical details

- Too many animations

- Too small fonts + bad use of color

- No match between what presenter says and what appears on the slides

Other key problems are:

- The final slide has no call to action

- The presenter spent too much time preparing the slides but no time practising them

SOLUTION Before you start preparing your presentation, you need to think deeply about the following:

i) Why did you choose your specific research topic? Simply saying that 'my professor told me to study it', or 'I like the topic' is not enough. You need to look inside yourself. Go back into your past, where was the seed sown? ii) Why is your research important to you, and why should it be important also for your audience and society in general? If you can't think of reasons for this, you will never be able to give a convincing presentation. iii) Why it is important to tell other people about it? Think in terms not only of the benefits, but also what would happen if your research was NOT carried out.

When you've really thought about these questions, then:

- Think about a captivating way to introduce your research in the first few slides.

- Give your audience a clear agenda (you can do this orally, you don't necessarily need a slide).

- Structure your presentation as follows: Description of problem + goals; method; results; implications and limitations.

- Be concise. Only put essential information on your slides.

IMPACT If you manage to put all the above into practice, you will be making a start to becoming a passionate, convincing, interesting, enthusiastic and confident presenter. This will hopefully gain you respect and credibility, people will want to contact you, people will want to work with you, and your publications will be read. 


\section{Presentations: Don't fill your sides with text. When you've finished your presentation look at it using the option 'slide sequence' - does it look clear and simple?}

FULL OF TEXT

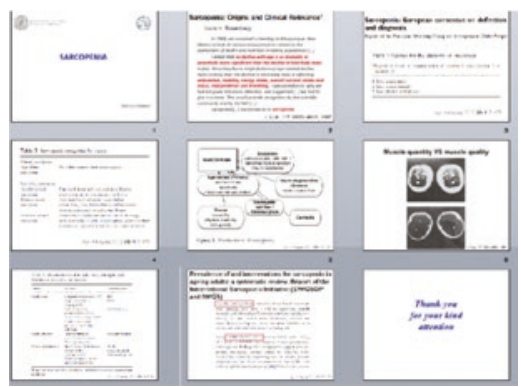

CLEAR \& SIMPLE

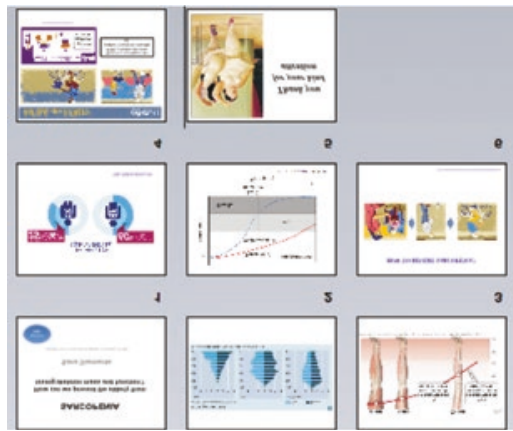

MISTAKE Few people would prefer to watch a presentation full of text rather than one with a mixture of text and images.

SOLUTION When you have created your slides, use the 'slide sequence' option to visualize all the slides together. If your slides look like the ones on the left, do not despair. You have not wasted your time. If you want you can use this text-full presentation to upload on the conference website or on your own website. This will enable people who couldn't come to your presentation to be able to fully understand your research project. This text-full version can also be downloaded before the conference by those members of the audience whose English may not be as good as yours - it will then enable them to follow you and your presentation more easily. Make sure that the text-full version follows the same order of slides as the clear $\&$ simple version.

For the 'live' presentation, the text-full version is unacceptable for the audience. And it also makes you as a presenter redundant: what can you say to the audience, when everything that you need to say is reported in the text on your slides? Instead, reduce your text to a minimum and focus on creating an aesthetically appealing presentation, where your job is not to read your slides but to interpret them and add extra information. 
94 Presentations: Ensure your title slide will immediately attract the attention of your audience (part 1).

1) NOT GREAT

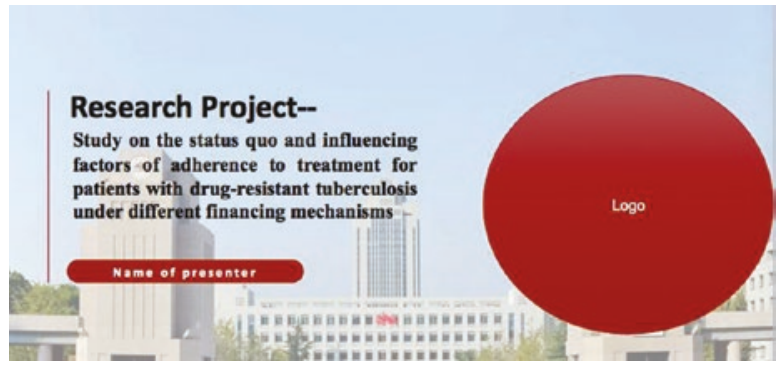

2) BETTER

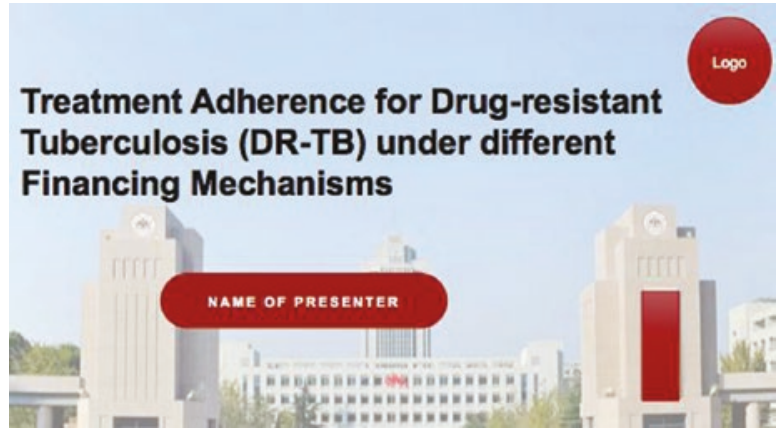

3) ALTERNATIVE

Why don't TB sufferers take their pills?

Treatment Adherence for Drug-resistant

Tuberculosis (DR-TB)
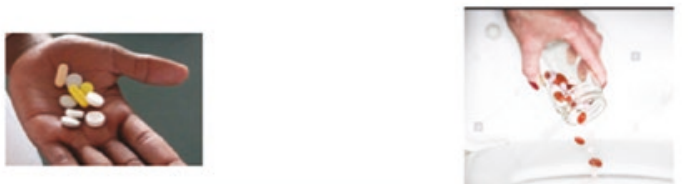


\section{EXAMPLE 1}

Your title has to attract the attention of your potential audience. 'Research project' provides no useful information. The key words 'drug resistant tuberculosis' (and 'financing mechanisms') are hidden in the text.

What are you going to say? With such a long title, your natural tendency is probably just to read it out. This adds no value for the audience and leads to an expectation for the audience of the usual boring presentation.

The logo is huge. Of course your institute is important, but it could just be highlighted in your final slide. The space that you give each item in a slide, should reflect its importance. Your name is much more important than the logo, consequently your name should be given more space.

The background image is of the researcher's institute. If the institute is internationally renown then maybe it's not a bad idea to have a picture of it. Otherwise something more interesting would be better.

\section{EXAMPLE 2}

The title is clear and pertinent. The logo is smaller and thus does not dominate the slide. The name is bigger and is placed in a central position. But the background image is still there and is not very memorable.

\section{EXAMPLE 3}

The aim of your title is to attract as many people as possible. A two-part title like this one uses a catchy question or statement to attract people who may be outside your strict field of research. The second part is a more technical explanation. However, this 2-part system means that you may have to reduce the amount that you write in the technical part - in this case the 'different financing mechanisms' is not mentioned. This may not be a bad thing as it gives you something of added value to say when you are talking about your first slide. You could show the slide, pause for 3-4 seconds, and then say: I am actually going about how different funding mechanisms can affect treatment adherence. This approach is far better than simply reading your title out.

Consider having photographs on your title slide. But there must be a reason for the photographs - i.e. they are pertinent to your topic. If you can't find any good photos, then don't put them. Also beware of copyright issues - the two photos used in this slide have been used without permission. It's probably a good idea to use noncopyrighted photos. 
95 Presentations: Ensure your title slide will immediately attract the attention of your audience (part 2).

1) NOT GREAT
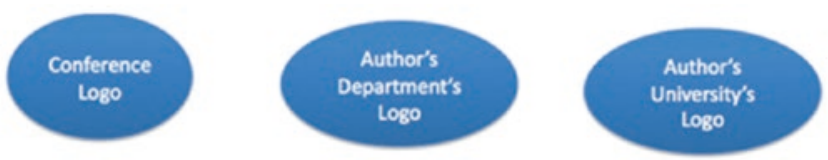

\section{SARCOPENIA}

S. Diamante, F. Corallo, G. Esmeraldo

Geriatric Unit, University Hospital, University of Italy

2) GOOD

\section{SARCOPENIA}

How can we prevent the elderly from losing skeleton mass and function?

\section{Sara Diamante}

Geriatric Unit, University Hospital, University of Italy 


\section{EXAMPLE 1}

The title simply tells the audience the topic. However, there is no indication of what aspect of the topic the presenter will be talking about.

Logos: Think about which logos are absolutely essential. For example, you may have a legally-binding contract to put your sponsor's name. But there is no need to put the conference logo (the audience know where they are!), and you can put your institute and university's logo in the final slide, if you think they are important.

Names: Don't put your name in a list of authors - you can put their names on the final slide as an acknowledgment. On the first slide, there should just be your name (yes, I know that others were involved in the project, but you are the one doing the presentation! However, there is nothing to stop you mentioning their names when you begin your talk). Don't just put the initial of the first name - put the whole name.

Tutors: Unless your tutors are known to your audience, there is no point putting them. Only put them if they will heighten your credibility (e.g. if they are Nobel prize winners!)

Basically, your aim is to create a clean slide where the key information (i.e. the title and your name) stand out.

\section{EXAMPLE 2}

This slide only contains essential information. From reading the title the audience will have a clear idea of: i) the topic (sarcopenia); ii) what sarcopenia is (the degenerative loss of skeletal muscle mass, quality, and strength associated with aging Wikipedia); and what the presenter's work focuses on (how to prevent this debilitating illness). Obviously, if the conference is dedicated to sarcopenia or all the audience are fully aware of what sarcopenia is, then the presenter could chose a more technical title.

Note: The text is in Arial rather than Times New Roman. Arial is one of the easiest to read (and in my opinion the most aesthetically pleasing) of the fonts commonly used in presentations. 


\section{Presentations: Consider having fun titles/double titles.}

DULL

Importance of elongation:

rice germination under anoxia

Chen Wang

Phn candidate

CONTACT FORCE DISTRIBUTION IN THE

INTERFERENCE FIT BETWEEN A HELICAL

SPRING AND A CYLINDRICAL SHAFT

Name 1, Name 2, Name 3

Department of Engineering Sciences

University of Modena and Reggio Emilia
FUN

\author{
Size is important: \\ rice germination under anoxia
}

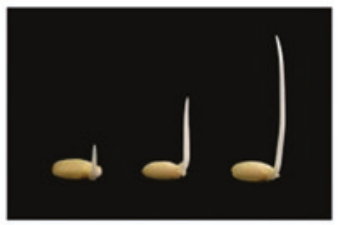

\section{Chen Wang}

WILL THIS FASTENER KILL ME?

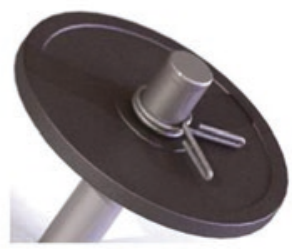

Roberto De Nero

MISTAKE A key issue in the world research is the mistaken belief that the main purpose of a presentation is to impart information about your project and results. That is true, but you also need to 'sell' your research, i.e. make your audience want to learn more about it, read your paper etc. Why do people go to presentations? They go to learn the state of the art, to get inspired for their own projects ... but your presentation will stand out more if the audience are also entertained and pleasantly surprised. Your aim is to attract as many people as possible, even those who are not strictly in your field. This will increase your network of contacts. And don't forget those who stand at the door of the presentation room, look in, and decide on the basis of the title slide whether they are going to sit down or go to a parallel session. Such people are unlikely to be inspired by the 'Dull' examples, but they will certainly have their curiosity stimulated by the 'Fun' examples. 
Are the 'Fun' examples professional? Yes. These are slides from two students of mine from around 2010 - both students have gone on to become real experts in their field - one in research, and the other founded a very successful engineering business.

SOLUTION It's good to be daring. But if you are not sure with the result or are not confident that you would be able to stand up and look at the audience while they are looking at your slide, then opt for something more conventional.

Note: The two presenters have used a slightly different approach in their fun versions. The first one has eliminated all reference to the technical aspect of the presentation (i.e. nothing about the contact force distribution). In doing so he may lose some members of the audience who will have no idea what the presentation is about (if they haven't looked at the conference program). But he has created curiosity, which I think will attract more people than it might lose. The other presenter has opted for a double title. The first part is humorous and is designed to attract attention. The second part is the 'technical' explanation. Both slides, IMHO, contain beautiful photographs - imagine them blown up to a huge screen size, they really will stand out from the other presentations in that session.

IMPACT You will get noticed. Being noticed means that it is then easier for you to make contact with people who you have never met before. You can say: You may remember me from the XXX conference last year, I was the one with the presentation entitled 'Size does matter'. Well, I was wondering whether .... 


\section{Presentations: Background slide: Don't cut \& paste paragraphs from other texts.}

\section{NOT GREAT}

\section{Background}

The 2018 WHO report pointed out that there are 10 million new cases of tuberculosis in the world, of which 558,000 are drug-resistant tuberculosis, and the number of drug-resistant tuberculosis cases in China ranks second in the world (13\%). The successful treatment rate for global drug-resistant tuberculosis is only $54 \%$.

From 2006 to 2014 , global fund projects covered 89 prefectures and cities in 30 provinces in China. Patients enrolled in the project can receive free treatment, medication supervision, health education and other services. After the end of the project in 2014, China's funding sources changed from international funds to government investment. The patient's treatment success rate and compliance have declined to varying degrees.

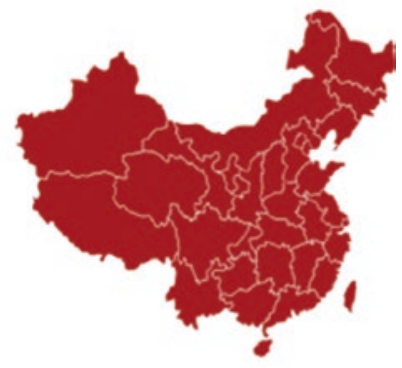

BETTER

\section{Background}

There are $\mathbf{1 0}$ million new cases of TB in the world, of which 558,000 are DR-TB (2018 WHO report)

The number of DR-TB cases in China ranks second in the world (13\%).

The cure rate is only $\mathbf{5 3} \%$. 


\section{EXAMPLE 1}

What word attracts the most initial attention in this slide? Answer: 'Background' This is because PowerPoint encourages you to have big bold headings. But 'background' is not a particular useful word for audiences to see. The presenter could choose a much more specific heading or simply have no heading at all and say: So this is the background to my study. And then say nothing for five seconds while the audience absorb the information.

How does the audience react when they see a lot of text? Either they read (while you are reading aloud) or they start looking at their phones. Many presenters lose their audience as soon as they show a slide full of text.

\section{EXAMPLE 2}

'Background' still attracts too much attention, but the text has been massively improved.

There is a lot of wasted space in the bottom part of the slide, making the slide look imbalanced. The solution is either to i) shift the text down to the central part of the slide; ii) add more text (but there is probably enough already); iii) add an image.

\section{EXAMPLE 3}

See Section 98. 


\section{Presentations: Presenting and talking about statistics.}

GOOD

10 million new cases of TB in the world, of which 558,000 are DR-TB (2018 WHO report)

Number of DR-TB cases in China ranks

second in the world (13\%).

Cure rate is only $? \%$.

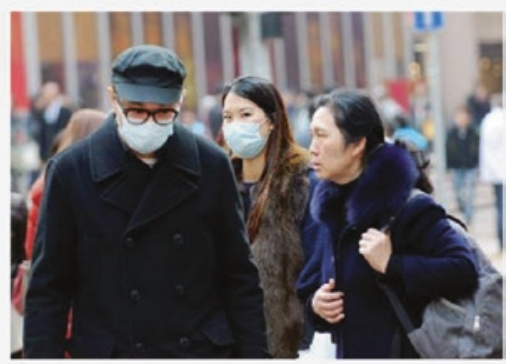

The above slide is an alternative slide for the Background slide shown in Section 97. I am putting it here because I have quite a few things to say about presenting statistics.

The heading 'Background' is gone. It is unnecessary. It is obvious that this is background info. Instead the speaker could say: Here are a few facts for you to look at. What do you think the cure rate might be? The strategy here is:

$>$ Don't read out what is written on your slides. Simply pause in silence for a few moments, and let the audience read the info.

$>$ The question mark attracts attention. It activates the audience's brains. They will want to know what the answer is and this wanting to know will increase their attention levels. Don't ask the question What is the cure rate? You don't actually want the audience to answer (though if this were a university lecture, then you would want students to come up with an answer). You just say: So the cure rate is only 53\%. That means that nearly half of sufferers don't get cured. And that means that ...

Let's talk a bit about statistics.

The key point in this slide is that you i) say the statistic - 53\%; ii) you say the statistic in a different way to drive you point home (nearly half); and iii) and then you say what the consequence is (And that means that ...). If you just say a statistic, the audience may not hear it or they may not understand what it means. 
Another point about this slide - it doesn't contain EVERYTHING the presenter knows about TB, just a few facts that fit nicely into the slide without making the audience work too hard at reading them. But this does not stop you (i.e. the presenter) having a few more statistics that you can add. You could say for example: $T B$ is curable. But it is still the second leading cause of death from infectious diseases worldwide. The situation was improving greatly until Covid-19. Many cases were either untreated or unnoticed during the lockdown. The medical world switched attention to finding a cure for the virus. The TB levels tragically returned to what they were in 2013. ... Here in China we rank second in the world for TB cases. Deaths from those who are also HIV-positive reach more than $20 \%$ in most countries in the WHO African Region. This highlights the inequities both in Africa, but also in a relatively advanced country such as China.

Note: If you are looking at these slides in color, then notice the 'red/vermillion' color. Did you know that many people find this color very hard to decipher? I would avoid all forms of red in order to help the color blind (1 in 12 men, and 1 in 200 women). If you want to see color versions of these slides then you can access our website: https://e4ac.com/english-for-research/ 


\section{Presentations: Don't overload audience with info. Make your statistics come alive by i) making comparisons and ii) activating your audience's brain.}

\begin{tabular}{|c|c|c|}
\hline \multicolumn{3}{|c|}{1} \\
\hline \multicolumn{3}{|c|}{$\begin{array}{l}\text { - There are three leaning towers in Pisa } \\
\text { - Designed by Bonanno Pisano } \\
\text { - Construction begins in } 1173 \text { (ends 1370) } \\
\text { - Galileo used it for experiments } \\
\text { - } 14,500 \text { tonnes } \\
\text { - Incination of } 38 \mathrm{~cm} \\
\text { - Only } 55.86 \mathrm{~m} \text { high } \\
\text { - } 294 \text { steps } \\
\text { - It leaned } 5.5 \text { degrees in } 1990 \\
\text { - One million tourists per year } \\
\text { - Five suicides per year } \\
\text { - Over } 40,000 \text { scientific articles written about the Tower } \\
\text { - Features in a Superman film }\end{array}$} \\
\hline \multicolumn{3}{|c|}{2} \\
\hline & Pisa & Paris \\
\hline Designed & Bonanno Pisano & Designed for Paris Expo \\
\hline Weight & 14,5000 & 10,000 \\
\hline Height & $55.86 \mathrm{~m}$ & $\begin{array}{l}320 \mathrm{~m} \text { (highest building for } \\
41 \text { years) }\end{array}$ \\
\hline Steps & 294 & 1665 \\
\hline Changes & $\begin{array}{l}5.5 \text { degrees in } \\
1990\end{array}$ & $\begin{array}{l}\text { Height varies by } 15 \mathrm{~cm} \text { due } \\
\text { to temperature changes }\end{array}$ \\
\hline Tourists & $1,000,000$ & $6,980,000$ \\
\hline Cost & $€ 25$ & $€ 15$ \\
\hline
\end{tabular}




\section{Pisa vs Paris}

1. Designed by Bonanno Pisano

2. Construction begins in 1173 (ends 1370)

3. 14,5000 tonnes

4. $55.86 \mathrm{~m}$ high

5. 294 steps

6. It leaned 5.5 degrees in 1990

7. One million tourists per year
1. Designed for Paris Expo

2. Intended to be demolished 1909

3. Weighs 10,000 tonnes. The paint weighs as much as 10 elephants

4. $320 \mathrm{~m}$ high (highest building for 41 years)

5. Lift cables cut when Hitler visited so he had to walk up the 1665 steps

6. Height varies by $15 \mathrm{~cm}$ due to temperature changes

7. 6.98 million (most visited paid monument in the world)

\section{4}

\section{Ture or False?}

In relation to the Leaning Tower, the Eiffel Tower

1. is six times taller

2. weighs one third less

3. changes height by $15 \mathrm{~cm}$ in summer

4. attracts seven times as many tourists

5. costs less to climb

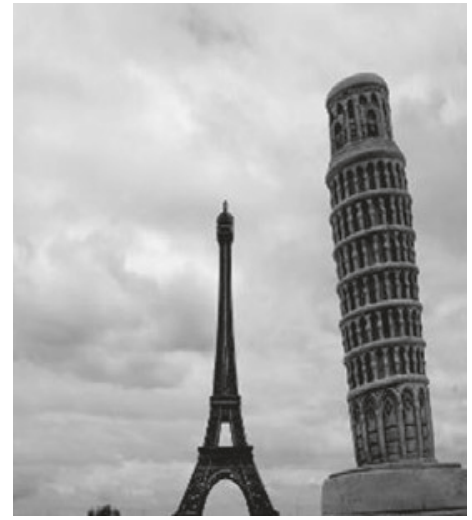

Let's imagine you are an art historian or work in cultural heritage sciences, and you want to give a few interesting statistics about the Leaning Tower of Pisa; or you an engineer describing a new means for preventing the tower from falling. You want a first slide that will attract attention and serve as an introduction to your topic by presenting some interesting statistics about the tower. 
There are many ways to present statistics and information in general, which are illustrated in the four examples above. Take a quick look at them and decide which one would be the most effective in a conference presentation. To see the original versions of the slides: https://e4ac.com/english-for-research/

\section{EXAMPLE 1}

This slide contains a lot of interesting info for the audience - but it's too much to absorb. And what is your role as a presenter? Do you read the facts out aloud, do you comment on them?

It also contains info that in itself is difficult to appreciate. For example, the tower weighs 15000 tonnes. Most people will have problems visualizing what 15000 tonnes is. And what does only in only 55.86m high mean? Only with respect to what? To make such statistics come alive you have to compare them with something else. The obvious comparison here is with the Eiffel Tower in Paris, which weighs two thirds the leaning tower but is nearly six times as high.

EXAMPLE 2 AND 3 These two slides present very similar info in different ways. The table is very clear and this slide would work well if it was in the part of the presentation where the presenter is dealing with technical aspects and the differences between the two towers. But in the context of getting the audience interested, it fails (well at least partially). The audience's brain does not have to make any mental effort (in a positive sense) to capture the information. Slide 3 presents similar info with a few more details. It is less easy to read because the points are not aligned.

EXAMPLE 4

The four slides are taken from my presentations courses (https://e4ac.com/courses/). Almost unanimously my students think that Slide 4 works best. This is because it:

1. is quick and easy to read - only five items, so no information overload

2. gets the audience to think before listening to the answers (and thus be more attentive in general throughout the rest of the presentation)

3. allows the presenter to then add other interesting information (e.g. superman, 40000 scientific articles, ten elephants-from Slide 1)

Three other important points:

4. You may argue that this kind of slide (Slide 4) is not serious or professional enough for a conference presentation. But having fun and being professional are not two opposing factors. The point is to find interesting ways to make your messages memorable. 
5. It is important to understand that you and your slides have different roles. The slides serve as a prop to help you remember what you are going to say, and they help to focus the audience. But you and your slides need to work together. You don't want your slides taking all the glory. By this I mean that Slide 4 works well because you can add some other exciting information to wow your audience.

6. There are no fixed rules. You should only do what you feel comfortable with. If Slide 2 is what you like to do, and Slide 4 is out of your comfort zone, then stick to Slide 2. However, maybe test out a Slide 4 approach on other occasions, e.g. during lectures rather than at an international conference. You and your audience will have fun using Slide 4. And if you have fun, then I guarantee you will give better presentations and you will feel more relaxed.

\section{SOLUTION}

Make a list of all your data and statistics.

Reduce them to 5-8 items.

Show your 5-8 items to colleagues and friends and ask them which items they find most interesting.

Choose a mix of interesting (irrespective of your research topic) and fundamental (i.e. in terms of your research) items.

Decide which items to show on the slides, and which ones you will only express orally.

Find a way to present your data so that the audience is actively involved.

Decide what kind of graphics or other format to present your chosen data. 
100 Presentations: Final slide - Writing Thanks for your attention is not enough.

1) NOT GREAT

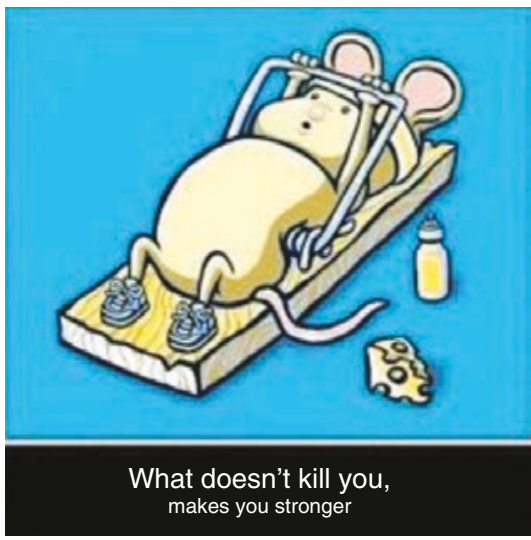

Thank you you for your kind attention

2) STILL NOT GREAT

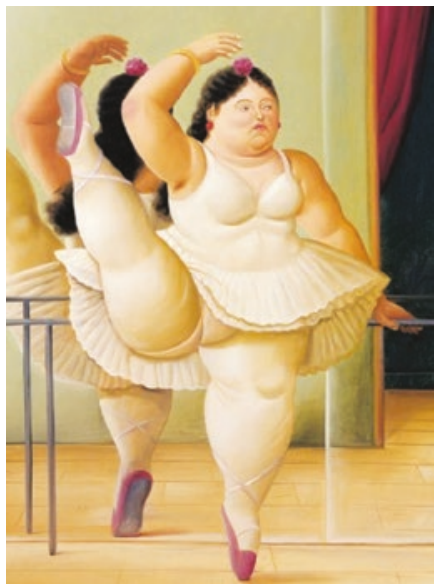

\section{Please \\ contact me for furuther info.}

sara.diamanti@unimi.it

3) GOOD

Conclusions: Help me (and them) get from A to C.

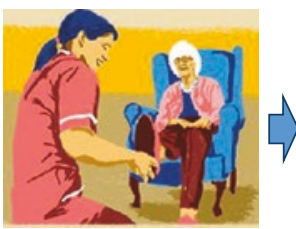

A

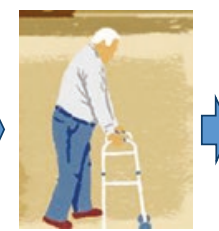

B

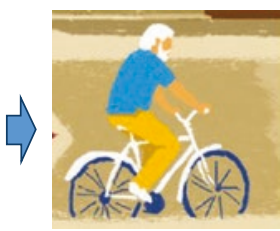

C

sara.diamanti@unimi.it 


\section{EXAMPLE 1}

How many times have you seen a presentation that ends: Thank you for your attention? How memorable is such a conclusions slide? This kind of slide achieves nothing other than telling the audience that the presentation is finally over. The picture is fun but the connection with sarcopenia (i.e. the topic of the presentation) is very obscure.

Note the yоu you - this is quite common when the same word appears on two different lines you may not notice the mistake. If you are the creator of a document it is very difficult for you yourself to see your mistakes. I strongly advise you to i) use an automatic spell checker; ii) show your slides to as many people as possible and get them to find the mistakes.

\section{EXAMPLE 2}

And how many times have you seen an amusing photo or picture in the last slide and wondered exactly what the connection is with the presentation? Will such an image + a phrase saying Please contact me have such an impact on the audience that they will be galvanized into action and immediately want to contact the presenter (either personally at the conference) or later via email? Unlikely. Will the spelling mistake (furuther) boost the presenter's credibility and underline how much time and effort he/she spent on preparing and checking the presentation? No.

\section{EXAMPLE 3}

The final slide is the last slide the audience sees. It serves a very special purpose. Its aim is to:

1. wake the audience up and inform them that you are about to finish your presentation

2. encourage the audience to read your publications and maybe to access the full version of your presentation online

3. remind the audience of who you are (and that you are a friendly and approachable person, not just a reliable researcher) and give them the means to contact you

4. provide reasons for the audience to contact you

5. help you set up future collaborations and get funding

The fourth and fifth points are the most important. They highlight that the role of your presentation is not merely to inform the audience about your research project. The aim is to get other researchers and institutes involved. Such institutes may have equipment that you don't have, and they may have the funds to invite you to spend time with them. 
So you need to tell the audience why they should contact you/why you need their help. Reasons to contact you include:

- you have encountered some difficulties in your research and need help

- you don't have a particular piece of equipment that maybe someone in the audience has

- you are looking for collaborators (if your institute is in an attractive place from a tourism point of view, then show them a photo to get them tempted to collaborate!)

- you have a limitation (e.g. small sample size) and are hoping that others could enable you to increase the size of the sample

The slide shown in the example has a very clear message. It shows the problem (elderly person with sarcopenia) and it shows where the presenter's research is heading. The title of the slide is a call to the audience for help. The presenter could also add other reasons for contacting her and explain where the audience can find more information about her project. Her email address is big and clear. 